Int. J. Morphol.,

32(4):1477-1483, 2014.

\title{
The Effects of Age and Sex on Brain Volume
}

\author{
Efectos de la Edad y del Sexo en el Volumen del Cerebro
}

Parvin-Dokht Bayat*; Ali Ghanbari**; Mojtaba Moradi*** \& Amir Raoofi:****

BAYAT, P. D.; GHANBARI, A.; MORADI, M. \& RAOOFI, A. The effects of age and sex on brain volume. Int. J. Morphol., 32(4):14771483, 2014.

SUMMARY: Age is associated with substantial macrostructural brain changes. While some recent CT scan studies have reported larger age affects in men than women, others find no sex differences, as brain morphometry is a potentially important tool in diagnosis and monitoring of age-related neurological diseases. A study was conducted on 147 Arakian healthy aged participants in the Department of Radiology, Valie asr Hospital, Arak city. Gray matter (GM), white matter (WM) and CSF was evaluated based on cranial CT scan images. Both males and females subjects were divided into four age groups. In this study, the subjects were $51.7 \%(76)$ male and $48.3 \%$ (71) female. Frequency of groups showed that the common types were in the 4th group of ages (65.1-80 years) with $44 \%$. Although, in $147 \mathrm{cases}$, all parameters were greater in male than female but no significant differences were seen. The significant differences between the two sexes were in length of cranium and width of cranium. There was significant difference between age groups in male and female. In male groups no significant difference was shown between them, but these were considered statistically significant in female groups in width of cranium $(\mathrm{p}=0.017)$, width of gray matter $(\mathrm{p}=0.008)$, length of cranium $(\mathrm{p}=0.052)$, length of white matter $(\mathrm{P}=0.024)$, distance of bicorn anterior $(\mathrm{p}=0.013)$, width of white matter in bicoronal Anterior $(\mathrm{p}=0.046)$, but in male age groups showed no statistically significant difference. We found changing in brain volume relationship with ageing in population, but this change in female is greater than male.

KEY WORDS: Ageing; CT scan; Morphometry.

\section{INTRODUCTION}

Although much is known about the general pattern of age effect on brain morphometry, the role of sex in brain aging is still controversial. Age is associated with substantial macro structural brain changes. Some studies have found more age-related regional volume differences in men than in women (Nunnemann et al., 2009). While some recent magnetic resonance imaging studies have reported larger age effects in men than women, others found no sex differences. Furthermore, knowledge of the patterns of brain shrinkage in normal aging could lead to better understanding of its causes and perhaps to interventions, lessening the loss of brain functions associated with brain shrinkage with age (Smith et al., 2007). During the past two decades, several studies have investigated the effect of aging on the human brain. More often than not, these studies investigated cerebral changes over life span (from 20 up to 80 years). Their findings have lead to a large consensus regarding the global morphological changes due to aging. First, postmortem studies have described, starting at the fourth decade, a decrease of the brain weight and an increase of the cerebrospinal fluid volume (CSF) (Dekaban, 1978) Postmortem analyses of brain structure depend on factors such as the interval between death and fixation, the timing of measurements, and the inclusion or exclusion of brain stem structures and meninges (which can be difficult to control), and hence vary across studies (Messert, 1972; Miller et al., 1980). Moreover, if brain weight is related to body height, the progressive increase in height over the past century may limit the applicability of conclusions from the significant fraction of postmortem studies that were conducted in the last century (Miller et al.) can be difficult to study. Therefore, studies using Magnetic Resonance Imaging (MRI) have confirmed and refined these findings by showing that the gray matter (GM) volume starts to decrease earlier in the life (at the end of the first decade), whereas white matter (WM) volume starts to decrease at the fourth decade (Courchesne et al., 2000; Pfefferbaum et al., 1994). Also, a number of in vivo imaging studies have attempted to quantify age-related change in whole brain volume, grey matter, white matter, and CSF compartments

* Department of Anatomy, the Arak Medical School, Arak University of Medical Sciences, Arak, Iran.

** Fertility and Infertility Research Center, Kermanshah University of Medical Sciences, Kermanshah, Iran.

*** Department of Biology, Islamic Azad University, Hamedan Branch, Hamedan, Iran.

${ }^{* * * *}$ Student Research Committee, Kermanshah University of Medical Sciences, Kermanshah, Iran. 
(Pfefferbaum et al., 1994). Latest studies showed sexual dimorphisms of adult brain volumes was more evident in the cortex, with women having larger volumes, relative to cerebrum size (Zaidi, 2010) In the present study, we have investigated this issue by taking advantage of a large epidemiology study dealing with subarachnoid space around brain aging for which 147 of subjects in their first or eighth decade were recruited and examined with CT scan.

\section{MATERIAL AND METHOD}

Cross-sectional study, using cranial CT scan obtained from Department of Radiology, Valie asr Hospital, Arak city. The age and sex were matched among 76 males and 71 females each, 147 cases. The study involved normal subjects from birth to 109 years, categorized into groups of 0-18 years, 18.1-40 years, 40.1-65 years and 65.1-80 years, and above 80 years. Only normal CT scans obtained from the Department of Radiology were measured in the Anatomy Department. Approval was sought from the Ethics committee of Arak Medical Science University before the study started. A written standard consent was taken from all subjects willing to be part of the study. After images acquisition, skull diameters were measured. Data collected were recorded on the performer, organized and entered on Excel spread sheet to be analyzed using SPSS 16 version, and statistical analysis involved paired comparisons of mean diameters. ANOVA was performed to define the correlation of parameters used in this study $\mathrm{P} \leq 0.05$ was considered statistically significant.

The conventional methodology was adopted for acquisition of lower parameters with a $1 \mathrm{~m}$ source film distance:

1- Posteroanterior axis of cranial bone (from inner table to inner table).

2- Anteroposterior axis of brain (external margin to external margin).

3- Transverse axis of cranial bone (The biparietal diameter (BP) is the major measurement

between parietals (from inner table to inner table).

4- Transverse axis of brain (external margin to external margin that gray matter is maximum).

5- Distance between apex of anterior horns of two lateral ventricles (there is white matter).

6- Distance between apex of posterior horns of two lateral ventricles (there is white matter).

7- Transverse axis of cranial bones (from inner table to inner table) at the level of apex of anterior horn.

8- Transverse axis of brain (external margin to external margin) at the level of anterior horn.
9- Transverse axis of cranial bone (from inner table to inner table) at the level of apex of posterior horn.

10- Transverse axis of brain (external margin to external margin) at the level of posterior horn.

11- Cerebro-spinal fluid in length space, posteroanterior axis of cranial bone-anteroposterior axis of brain.

12- Cerebro-spinal fluid in width space, transverse axis of cranial bone-transvers axis of brain.

13- Cerebro-spinal fluid in width space in apex of anterior horn, transverse axis of cranial bone- transverse axis of braintransverse axis of brain the level of anterior horn.

14- Cerebro-spinal fluid in width space in apex of posterior horn, transverse axis of cranial bone- transverse axis of braintransverse axis of brain the level of posterior horn.

\section{RESULTS}

In this study, 147 cases were involved $51.7 \%$ (76) were male and $48.3 \%$ (71) were female and we divided cases into five groups: 1 group $=0-18$ years old, 2 group $=18.1-40$ years old, 3 group $=40.1-65,4$ group $=65.1-$ 80 and 5 th group $=>80$ and Frequency of groups showed in Table I, that there common types were 4th groups with $44 \%$. Table II showed Descriptive Statistics of parameters of brain ventricles and cranium and white matter. Table III showed Mean and Standard Deviation of cranium parameters in male and female separately. That all parameters are greater male than female but no significance difference between them except, length of cranium and width of cranium that they have significance difference (Table IV) between male and female population. In Table IV showed significance difference between groups of age in male and female. In male groups showed no significance difference between them but there were considered statistically significant in female groups in width of cranium $(\mathrm{p}=0.017)$ width of gray matter $(\mathrm{p}=0.008)$ length of cranium $(\mathrm{p}=0.052)$ length of white matter $(\mathrm{P}=0.024)$ distance of bicorn anterior $(\mathrm{p}=0.013)$ width of white matter in bicoronal Anterior $(\mathrm{p}=0.046)$ but in male age groups no statistically significant.

Table I. Frequency and percent of ageing categories in Arakian sampled population.

\begin{tabular}{lcc}
\hline Groups & Frequency & Percent $(\boldsymbol{\%})$ \\
\hline $0-18$ & 11 & 6.9 \\
$18.1-40$ & 16 & 10.3 \\
$40.1-65$ & 44 & 30.3 \\
$65.1-80$ & 43 & 29.7 \\
$>80$ & 33 & 22.8 \\
Total & 147 & 100.0 \\
\hline
\end{tabular}


Table II. Mean and Standard Deviation of parameters in male and female separately in Arakian sampled population.

\begin{tabular}{|c|c|c|c|c|}
\hline & Sex & $\mathbf{n}$ & Mean & S.D \\
\hline \multirow{2}{*}{ Width of cranium } & Female & 76 & 50.22 & 10.76 \\
\hline & Male & 71 & 51.59 & 15.02 \\
\hline \multirow{2}{*}{ Width of grey matter } & Female & 76 & 42.96 & 9.89 \\
\hline & Male & 71 & 44.57 & 13.44 \\
\hline \multirow{2}{*}{ Length of cranium } & Female & 76 & 61.10 & 12.29 \\
\hline & Male & 71 & 64.35 & 17.24 \\
\hline \multirow{2}{*}{ Length of white matter } & Female & 76 & 53.18 & 11.05 \\
\hline & Male & 71 & 56.21 & 15.77 \\
\hline \multirow{2}{*}{ Width white matter in bicoronal Anterior } & Female & 64 & 37.85 & 8.50 \\
\hline & Male & 59 & 38.79 & 12.31 \\
\hline \multirow{2}{*}{ Width cranium bone in bicoronal Anterior } & Female & 63 & 42.46 & 12.17 \\
\hline & Male & 59 & 43.38 & 13.90 \\
\hline \multirow{2}{*}{ Width with matter in bicoronal posterior } & Female & 62 & 39.24 & 10.85 \\
\hline & Male & 59 & 40.79 & 12.77 \\
\hline \multirow{2}{*}{ Width cranium bone in bicoronal posterior } & Female & 62 & 46.37 & 10.75 \\
\hline & Male & 59 & 47.10 & 14.07 \\
\hline \multirow{2}{*}{ Distance bicoronal anterior } & Female & 64 & 11.06 & 3.24 \\
\hline & Male & 58 & 11.26 & 4.28 \\
\hline \multirow{2}{*}{ Distance white matter in bicoronal posterior } & Female & 62 & 20 & 8.15 \\
\hline & Male & 58 & 20.74 & 8 \\
\hline \multirow{2}{*}{ Width csf1 length } & Female & 76 & 7.26 & 1.66 \\
\hline & Male & 71 & 7 & 1.60 \\
\hline \multirow{2}{*}{ Width csf 2 transverse } & Female & 76 & 7.82 & 2.20 \\
\hline & Male & 71 & 8.14 & 2.02 \\
\hline \multirow{2}{*}{ Width Csf3 bicoronal ant } & Female & 63 & 4.46 & 3.27 \\
\hline & Male & 59 & 4.52 & 3.302 \\
\hline \multirow{2}{*}{ Width Csf4 bicoronal post } & Female & 62 & 7.12 & 3.10 \\
\hline & Male & 59 & 6.3 & 2.62 \\
\hline
\end{tabular}

Csf1 $1=$ difference between length of cranium white matter. Csf02 $=$ difference between width of cranium and white matter. $\mathrm{Csf}=$ bicoronal Ant: difference between width of cranium and with matter in anterior horn of ventricle. $\mathrm{Csf}=$ bicoronal post: difference between width of cranium and with matter in posterior horn of ventricle.

Table III. Descriptive Statistics of parameters of brain CSF spaces and cranium and white matter in Arakian sampled population.

\begin{tabular}{lccccc}
\hline & n & Minimum & Maximum & Mean (mm) & S.D \\
\hline Width of cranium & 137 & 26.00 & 84.00 & 50.54 & 12.78 \\
Width of gray matter & 137 & 23.00 & 74.00 & 43.32 & 11.44 \\
Length of cranium & 137 & 35.00 & 100.00 & 62.34 & 14.81 \\
Length of white matter & 137 & 27.00 & 90.00 & 54.21 & 13.26 \\
Distance of bicorn anterior & 115 & 5.00 & 20.00 & 11.16 & 3.68 \\
Width of white matter bicoronal Anterior & 116 & 16.00 & 69.00 & 38.10 & 10.35 \\
Width cranium bone bicoronal Anterior & 115 & 10.00 & 81.00 & 42.80 & 13.01 \\
Distance of bicoronal posterior & 113 & 10.00 & 65.00 & 20.29 & 8.15 \\
Distance with matter bicoronal posterior & 114 & 14.00 & 72.00 & 39.87 & 11.83 \\
Width of cranium bone bicoronal posterior & 114 & 23.00 & 80.00 & 46.72 & 12.50 \\
Width c.s.f. 1(in length) & 137 & 1 & 15.00 & 7.15 & 1.61 \\
Width c.s.f.2 (in transvers) & 137 & 0.00 & 17.00 & 8.44 & 1.67 \\
Width C.s.f3 (in bicoronal anterior) & 115 & 1 & 16.00 & 6.6 & 1.54 \\
Width C.s.f4 (in bicoronal posterior) & 114 & 0.00 & 22.50 & 6.64 & 2.59 \\
Age (years) & 137 & 6.00 & 109.00 & 45.70 & 23.14 \\
\hline
\end{tabular}


Table IV. Comparative parameters between male (M) and female (F) groups and also between female and male $(\mathrm{F} / \mathrm{M})$ groups (significant difference were set at $\mathrm{p}>0.05)$.

\begin{tabular}{lccc}
\hline & & F & M \\
\hline Width of cranium & 0.023 & 0.017 & 0.870 \\
Width of gray matter & 0.077 & 0.008 & 0.673 \\
Length of cranium & 0.015 & 0.052 & 0.313 \\
Length of white matter & 0.025 & 0.024 & 0.335 \\
Distance of bicorn anter ior & 0.111 & 0.013 & 0.112 \\
Width of white matter in bicoronal anterior & 0.237 & 0.046 & 0.409 \\
Width cranium bone in bicoronal anterior & 0.162 & 0.159 & 0.847 \\
Distance of bicoronal posterior & 0.878 & 0.159 & 0.049 \\
Width of white matter in bicoronal posterior & 0.636 & 0.087 & 0.04 \\
Width of cranium bone in bicoronal posterior & 0.086 & 0.098 & 0.778 \\
Grey and white matter 2 & 0.43 & 0.07 & 0.55 \\
Width csf length cranium & 0.065 & 0.089 & 0.846 \\
Width csf transvers cranium & 0.067 & 0.119 & 0.604 \\
Width Csf in bicoronal anterior & 0.373 & 0.181 & 0.712 \\
Width Csf in bicoronal posterior & 0.182 & 0.189 & 0.064 \\
\hline
\end{tabular}

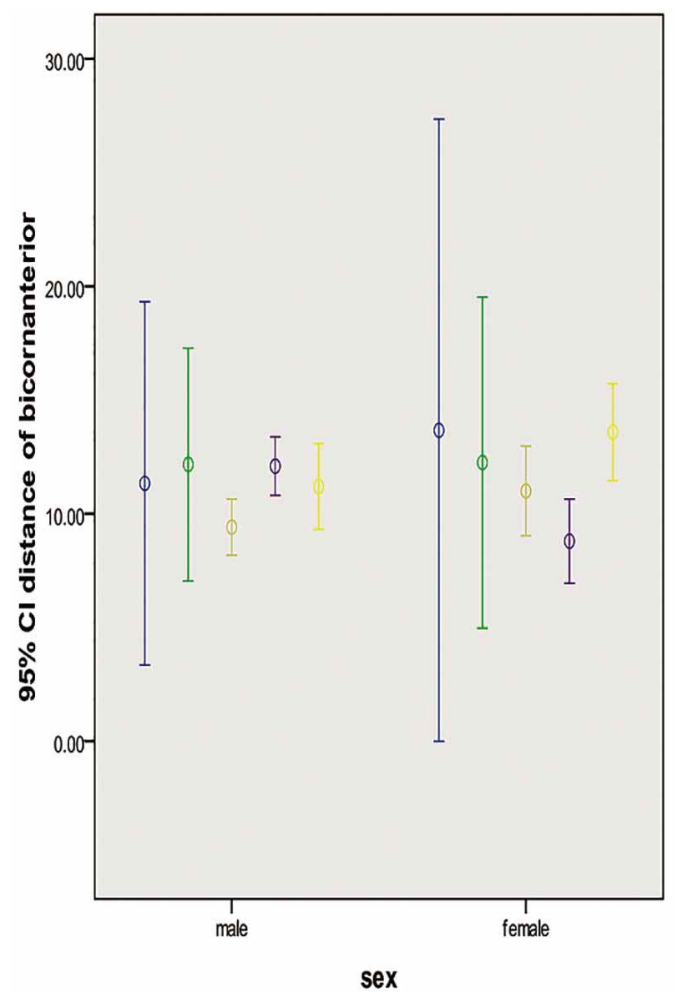

Fig. 1. Comparative white matter in 5 groups in male and female.

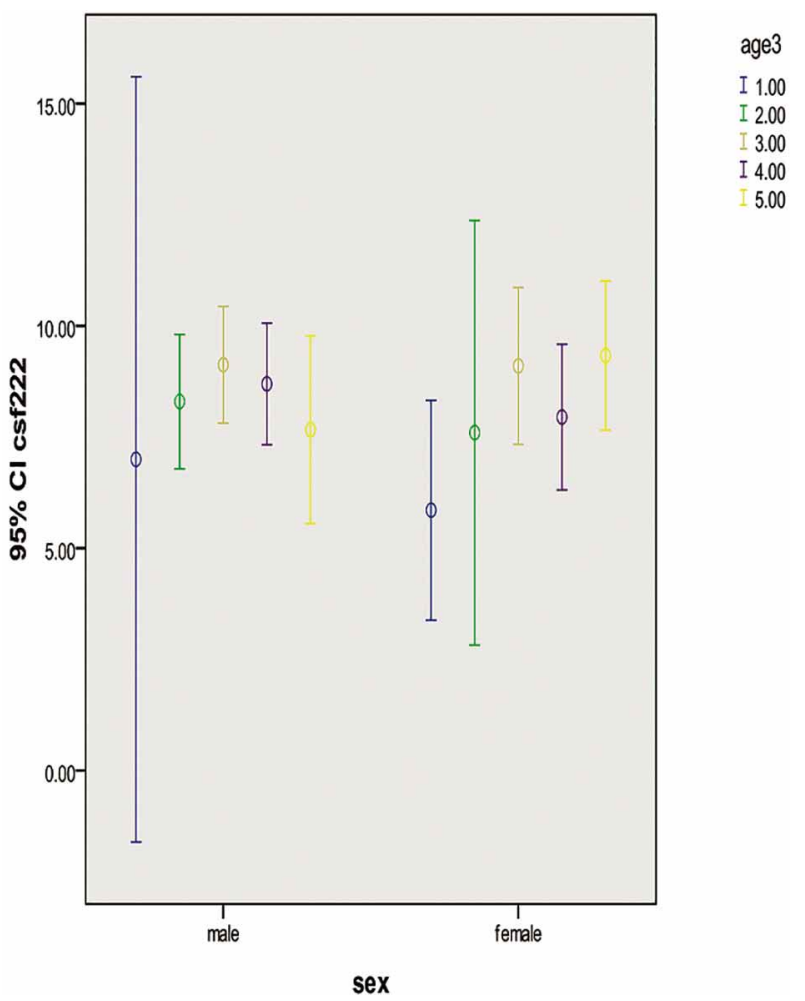

Fig. 2. Comparative CSF space in five ageing groups in male and female. 


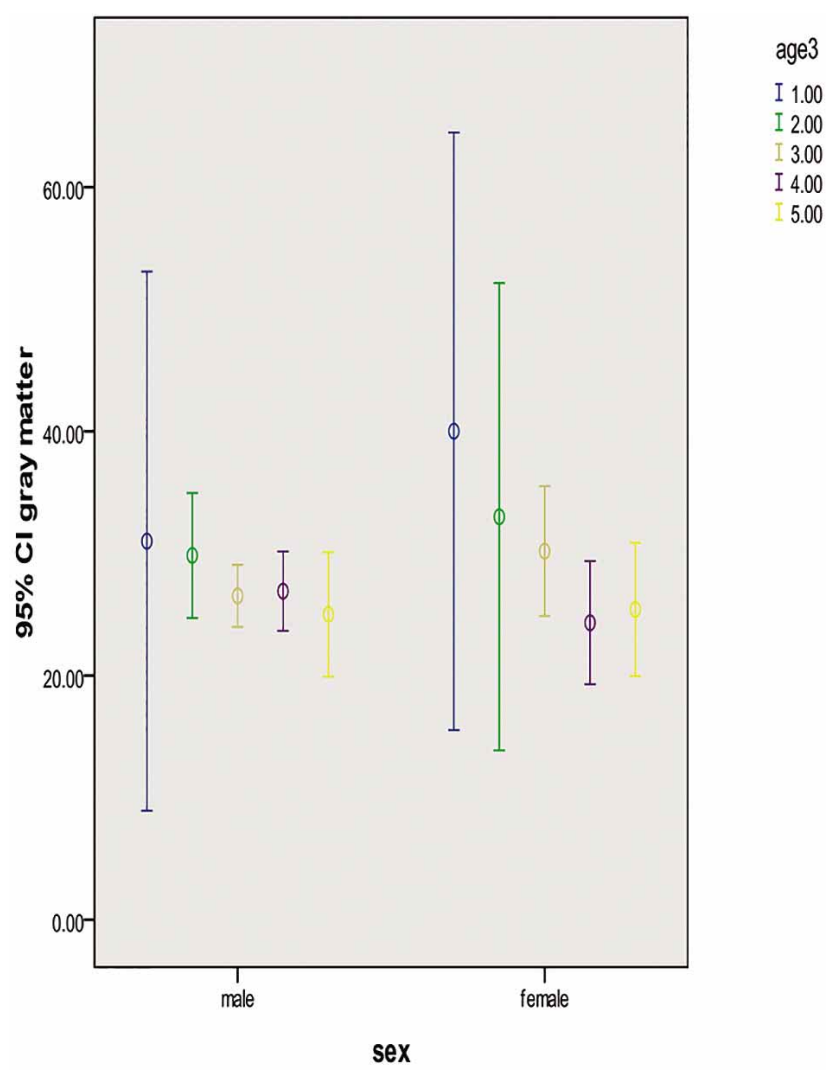

Fig. 3. Comparative gray matter in 5 ageing groups in male and female.

\section{DISCUSSION}

The field of nervous system structural neuroimaging has been growing rapidly in response to the realization of the complexity and potential malleability of postnatal brain development. Large-scale studies are underway in several countries combining data from multiple sites in order to increase sample sizes and move towards the compilation of population-based measures of brain development. Advances in scanner technology are making it possible to obtain very high-resolution structural data within time frames feasible for every age group populations (Lenroot \& Giedd, 2006). Age-associated changes in the liner measurements of the four intracranial compartments have interested many investigators. To our knowledge, however, the current study is the first to employ CT scans, standardized protocols, careful screening of healthy subjects, and age and sexmatching of subjects by decade. Before discussing our results in details, it is also worthwhile discussing the intrinsic limitations of cross-sectional studies, such as ours, where age effects on neuroanatomy are measured at a single time across a sample of subjects having different ages. Our study showed significance difference between groups of age in male and female. In male groups it showed no significance difference between them but these were considered statistically significant in female groups in width of cranium $(\mathrm{p}=0.017)$ width of gray matter $(\mathrm{p}=0.008)$ length of cranium $(\mathrm{p}=0.052)$ length of white matter $(\mathrm{P}=0.024)$ distance of bicorn anterior $(\mathrm{p}=0.013)$ width of white matter in bicoronal Anterior $(\mathrm{p}=0.046)$ but in male age groups no statistically significant. Although, many of our results are consistent with previous reports, some are not, we believe that these differences are most likely related to differences in image quality and subject selection. Many neuropathological studies show that normal ageing is characterized by a substantial and extensive loss of neurons in the cerebral cortex, although this is controversial, with stereological investigations indicating little neuronal loss with normal ageing (Gunning-Dixon et al., 1998), and some reports suggesting that alterations in cerebral white matter and subcortical neuronal loss may be the predominant effect of age (Guttmann et al., 1998). We found changing in brain volume relationship with ageing in population, but this changing in female is greater than male. This changing is white matter is significant. Pfefferbaum et al. (1992), suggest that ageing predominantly and substantially affects the grey matter. Others have suggested accelerated ageing in the later decades of life (Pruessner et al., 2001). Jacoby et al., examined 50 psychiatrically and neurologically healthy volunteers from the community to establish genuine normative standards for CT scans in the elderly, they found only a non-significant trend to larger ventricles with age, but this may be due to the lack of persons under the age of 62 years in their survey (Jacoby et al., 1980). Objective measurements are required for the initial diagnosis of CSF space enlargement and are essential for assessing subsequent changes in subarachnoid space, White matter, gray matter. Our study provides reference ranges for the linear measurements of intracranial measurements of Transverse and length lines in male and female groups, there were significant differences between transverse width of white matter, white matter of distance between posterior horn, distance between posterior horn and external border of brain and length of brain. In groups of males from 0 to 109 years of age, there were no significant differences except white mater in distance between two posterior horn, but in between groups of female from 0 to 109 years of age, there were significant differences in width of cranium, width of white matter, length of white mater, white matter of distance between posterior horn, white matter of distance between anterior horn, distance between posterior horn and external border of brain and length of brain. Our study provides reference ranges for the linear measurements of all four intracranial subarachnoid spaces in five groups from 0 to 109 years age. The measurements of the CSF compartments 
were distance between external border of brain and internal surface of cranium diameters in the corresponding CT section, in order to take into account the size and shape of the growing skull in four sided. All CSF spaces were relatively larger in the male (Table III) than in the female separately, but did not differ significantly between them, since the cranial size was taken into account. Moreover, in male and female totally, did not show difference between groups. We did not find significant difference, increases in CSF spaces in males compared with females. However, some previous studies have found greater increases in CSF spaces in males compared with females (Coffey et al., 1998; Gur $e t$ al., 1991). Although this has not been reproduced by others (Good et al., 2001). The cause of sex differences in brain atrophy with aging is still unclear and may be attributed to internal and external factors. Sex hormones may be involved in the former, whereas the natural environment, family circumstances, education, and habits (such as smoking and alcohol) may be involved in the latter. Compared with external factors, levels of sex hormones are relatively stable between individuals, so the effect of sex hormones on brain structures may be more important. For example, testosterone level is significantly correlated with the weight of the brain and hippocampus in animal experiments (Perrot-Sinal et al., 1998). Testosterone administration enhances spatial cognition in older men (Janowsky et al., 1994). which suggests a relationship between testosterone, brain volume, and spatial cognition. Some authors have indicated that there are sex differences in brain metabolism in different regions of the brain (Gur et al., 1995). These differences are most marked in the same regions as those in which we found sex differences, such as the temporal and parietal lobes and the cerebellum. Because few published studies have investigated changes in brain structure and metabolism with aging in the same subjects and regions, the mechanism of brain atrophy with aging is not entirely clear (Xu et al., 2000).

\section{ACKNOWLEDGMENTS}

The paper is derived from a thesis conducted at two Kermanshah and Arak Universities of Medical Sciences.

BAYAT, P. D.; GHANBARI, A.; MORADI, M. \& RAOOFI, A. Efectos de la edad y del sexo en el volumen del cerebro. Int. J. Morphol., 32(4):1477-1483, 2014.

RESUMEN: La edad se asocia con cambios cerebrales sustanciales. Mientras que algunos estudios recientes han reportado que la edad afecta a hombres más que a mujeres, otros no encuentran diferencias sexuales. La morfometría cerebral es una herramienta potencialmente importante en el diagnóstico y seguimiento de enfermedades neurológicas relacionadas con la edad. Se realizó un estudio en 147 participantes sanos de edad avanzada en el Departamento de Radiología, Hospital de Valie asr, ciudad de Arak. La sustancia gris (SG), sustancia blanca (SB) y líquido cerebro-espina (LCR) fueron evaluados en base a imágenes craneales de escáner CT. Los sujetos, hombres y mujeres fueron divididos en cuatro grupos etarios. De los sujetos incluidos en el estudio, $51,7 \%$ (76) fueron hombres y $48,3 \%$ (71) mujeres. La frecuencia de los grupos mostró que los tipos más comunes estaban en el cuarto grupo etario de (65,1 a 80 años) con un 44\%. En 147 casos todos los parámetros fueron mayores en hombres que en mujeres, sin embargo, no se observaron diferencias significativas. Entre los dos sexos las diferencias significativas estaban en longitud de cráneo y ancho del cráneo. No hubo diferencias significativas entre los grupos etarios. En los grupos de hombres, no se demostró ninguna diferencia significativa, pero éstos fueron considerados estadísticamente significativos en ancho de cráneo ( $\mathrm{p}=0,017)$, ancho de cráneo de las mujeres, la sustancia gris ( $\mathrm{p}=0,008)$, longitud del cráneo $(\mathrm{p}=0,052)$, longitud de la sustancia blanca $(\mathrm{P}=0,024)$, distancia anterior del bicornio $(\mathrm{p}=0,013)$ y el ancho de la sustancia blanca bicoronal anterior $(\mathrm{p}=0,046)$. Sin embargo en los grupos de edad de sexo masculino no se observaron diferencias estadísticamente significativas. Encontramos cambios en relación al volumen cerebral con el envejecimiento de la población; este cambio en el sexo femenino es mayor que el masculino.

PALABRAS CLAVE: Envejecimiento; Tomografía Computadorizada; Morfometría.

\section{REFERENCES}

Coffey, C. E.; Lucke, J. F.; Saxton, J. A.; Ratcliff, G.; Unitas, L. J.; Billig, B. \& Bryan, R. N. Sex differences in brain aging: a quantitative magnetic resonance imaging study. Arch. Neurol., 55(2):169-79, 1998

Courchesne, E.; Chisum, H. J.; Townsend, J.; Cowles, A.; Covington, J.; Egaas, B.; Harwood, M.; Hinds, S. \& Press, G.
A. Normal brain development and aging: quantitative analysis at in vivo MR imaging in healthy volunteers. Radiology, 216(3):672-82, 2000.

Dekaban, A. S. Changes in brain weights during the span of human life: relation of brain weights to body heights and body weights. Ann. Neurol., 4(4):345-56, 1978. 
Good, C. D.; Johnsrude, I. S.; Ashburner, J.; Henson, R. N.; Friston, K. J. \& Frackowiak, R. S. Voxel-Based Morphometric Study of Ageing in 465 Normal Adult Human Brains. Neuroimage, 14(1 Pt. 1):21-36, 2001.

Gunning-Dixon, F. M.; Head, D.; McQuain, J.; Acker, J. D. \& Raz, N. Differential aging of the human striatum: a prospective MR imaging study. A. J. N. R. Am. J. Neuroradiol., 19(8):1501-7, 1998.

Gur, R. C.; Mozley, P. D.; Resnick, S. M.; Gottlieb, G. L.; Kohn, M.; Zimmerman, R.; Herman, G.; Atlas, S.; Grossman, R. \& Berretta, D. Gender differences in age effect on brain atrophy measured by magnetic resonance imaging. Proc. Natl. Acad. Sci. USA, 88(7):2845-9, 1991.

Gur, R. C.; Mozley, L. H.; Mozley, P. D.; Resnick, S. M.; Karp, J. S.; Alavi, A.; Arnold, S. E. \& Gur, R. E. Sex differences in regional cerebral glucose metabolism during a resting state. Science, 267(5197):528-31, 1995.

Guttmann, C. R.; Jolesz, F. A.; Kikinis, R.; Killiany, R. J.; Moss, M. B.; Sandor, T. \& Albert, M. S. White matter changes with normal aging. Neurology, 50(4):972-8, 1998.

Jacoby, R. J.; Levy, R. \& Dawson, J. M. Computed tomography in the elderly: I. The normal population. Br. J. Psychiatry, 136:249-55,1980.

Janowsky, J. S.; Oviatt, S. K. \& Orwoll, E. S. Testosterone influences spatial cognition in older men. Behav. Neurosci., 108(2):325-32, 1994.

Lenroot, R. K. \& Giedd, J. N. Brain development in children and adolescents: insights from anatomical magnetic resonance imaging. Neurosci. Biobehav. Rev., 30(6):718-29, 2006.

Messert, B.; Wannamaker, B. B. \& Dudley, A. W. Jr. Reevaluation of the size of the lateral ventricles of the brain. Postmortem study of an adult population. Neurology, 22(9):941-51, 1972.

Miller, A. K.; Alston, R. L. \& Corsellis, J. A. Variation with age in the volumes of grey and white matter in the cerebral hemispheres of man: measurements with an image analyser. Neuropathol. Appl. Neurobiol., 6(2):119-32, 1980.

Nunnemann, S.; Wohlschläger, A. M.; Ilg, R.; Gaser, C.; Etgen, T.; Conrad, B.; Zimmer, C. \& Mühlau, M. Accelerated aging of the putamen in men but not in women. Neurobiol. Aging, 30(1):147-51, 2009.

Perrot-Sinal, T. S.; Kavaliers, M. \& Ossenkopp, K. P. Spatial learning and hippocampal volume in male deer mice: relations to age, testosterone and adrenal gland weight. Neuroscience, 86(4):1089-99, 1998.

Pfefferbaum, A.; Lim, K. O.; Zipursky, R. B.; Mathalon, D. H.; Rosenbloom, M. J.; Lane. B.; Ha, C. N. \& Sullivan, E. V. Brain gray and white matter volume loss accelerates with aging in chronic alcoholics: a quantitative MRI study. Alcohol Clin. Exp. Res., 16(6):1078-89,1992.

Pfefferbaum, A.; Mathalon, D. H.; Sullivan, E. V.; Rawles, J. M.; Zipursky, R. B. \& Lim, K. O. A quantitative magnetic resonance imaging study of changes in brain morphology from infancy to late adulthood. Arch. Neurol., 51(9):874-87,1994.

Pruessner, J. C.; Collins, D. L.; Pruessner, M. \& Evans, A. C. Age and gender predict volume decline in the anterior and posterior hippocampus in early adulthood. J. Neurosci., 21(1):194200, 2001.

Smith, C. D.; Chebrolu, H.; Wekstein, D. R.; Schmitt, F. A. \& Markesbery, W. R. Age and gender effects on human brain anatomy: a voxel-based morphometric study in healthy elderly. Neurobiol. Aging, 28(7):1075-87, 2007.

Xu, J.; Kobayashi, S.; Yamaguchi, S.; Iijima, K.; Okada, K. \& Yamashita, K. Gender Effects on Age-Related Changes in Brain Structure. AJNR Am. J. Neuroradiol., 21(1):112-8, 2000.

Zaidi, Z. F. Gender differences in human brain: A review. Open Anat. J., 2:37-55, 2010.

\section{Correspondence to:}

Ali Ghanbari

Fertility and Infertility Research Center

Kermanshah University of Medical Sciences

Kermanshah, P.O. Box 1568

IRAN

Email: aghanbari@kums.ac.ir

Received: 03-04-2014

Accepted: 24-10-2014 